\title{
Activity of Cytochrome p450 as a Steroidogenesis and Oxidation Catalyst of Cholesterol in Experimental Animals Exposed to Cigarette Smoke
}

\author{
Arni Amir ${ }^{1 *}$, M. Saka Abeiasa ${ }^{2}$, Oktavianis Oktavianis ${ }^{3}$ \\ ${ }^{1}$ Department of Biology, Faculty of Medicine, Andalas University, Padang, Indonesia; ${ }^{2}$ Department of Nursing, STIKES Piala \\ Sakti, Pariaman, Indonesia; ${ }^{3}$ Master's Program in Public Health, Faculty of Health, Fort De Kock University, Bukittinggi, West \\ Sumatra Indonesia
}

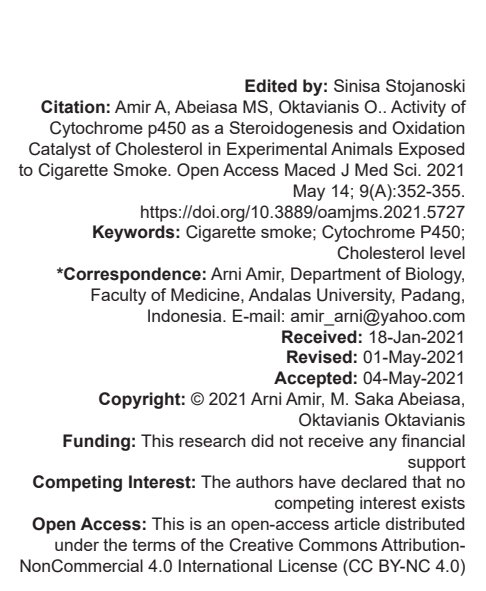

\begin{abstract}
BACKGROUND: Basically, body regulates various harmful substances, including nicotine and tar which were carried by cigarette smoke. Nicotine which accumulated in blood was transported to liver to be metabolized and excreted in kidneys. The metabolism of nicotine into a harmless substance to body is closely related to the role of cytochrome P450 enzyme. In liver, nicotine was catalyzed by cytochrome P450 to be intermediate nicotine- $\Delta-1$ ' ( 5 ') - iminium ion. The elevation of cholesterol leads the P450 to discard overage cholesterol to keep cholesterol homeostasis and atheroprotection.

AIM: The aim of the study was to determine the activity of cytochrome P450 to cigarette smoke exposure and to cholesterol level.

MATERIALS AND METHODS: A total of 32 Rattus norvegicus male Wistar albino strain was exposed to cigarette smoke with a different number of cigarettes for 57 weeks (2, 3, and 4 cigarette/day group, with a group of control). In the $58^{\text {th }}$ week, the blood of rats was collected for enzyme-linked immunosorbent assay analysis.

RESULTS: Both cytochrome P450 activity and cholesterol level affected to cigarette smoke exposure $(p>0.05,0.00$ for cholesterol levels and 0.04 for p450 levels).

CONCLUSIONS: Exposure of cigarette smoke significantly has an impact on increasing cholesterol levels and decreasing the activity of P450 enzyme. The elevating of cigarette number had a significant impact between the smoker and non-smoker groups.
\end{abstract}

\section{Introduction}

The Southeast Asia Tobacco Control Alliance report entitled The Tobacco Control Atlas, Association of Southeast Asian Nations (ASEAN) Region showed that Indonesia was the country with the highest number of smokers in ASEAN (65.19 million people), equivalent to $34 \%$ of the total population of Indonesia (2016). Around $79.8 \%$ of smokers bought cigarettes at kiosks, stalls, or minimarkets, and $17.6 \%$ bought cigarettes from supermarkets. There were 2.5 million outlets of cigarette retailers in Indonesia [1].

Basic Health Research (RISKESDAS) [2] released data that $85 \%$ of households in Indonesia were exposed to cigarette smoke. Approximately eight smokers died due to active smoking and one passive smoker died from smoke cigarette exposure of active smokers. Based on this ratio, at least 25.000 deaths in Indonesia occurred due to others smoke cigarette. About 4000 chemicals were detected in cigarette smoke, and nicotine was active chemical with the highest amount. Nicotine was responsible for various physiological changes that lead to patho-physical occurrence such as malignancy, hypoxia, and other systemic disorders. In other reports, pure nicotine was also known to have very high levels of toxicity.

Not only nicotine, other substances in cigarette smoke that potentially as strong toxin for humans included carcinogenic $\mathrm{N}$-nitrosonornicotine, nitrosamine (specifically due to fermentation and drying of tobacco leaves) [3]. Specifically, more than 43 carcinogens were found in cigarettes, cigarette smoke had a high concentration of naphthalene and polycyclic aromatic hydrocarbons, which were known to have active carcinogenic activity and have detrimental effects in the body [4].

Basically, body regulates various harmful substances, both drugs, and other substances, including nicotine and tar, contained cigarette smoke. Nicotine which accumulated in blood was metabolized and excreted through kidneys. The metabolism of nicotine became a friendly substance in the body was related to the role of cytochrome P450 enzyme. In liver, nicotine entered two metabolic pathways. First, nicotine was catalyzed by cytochrome $P 450$ to intermediate nicotine- $\Delta-1$ ' (5') 
- iminium ion, the ion entered the oxidation process to be cotinine by aldehyde oxidase in cytosol. Other nicotine metabolism products except cotinine were trans-3'hydroxycotinine and nicotine N'-oxide [5].

Continuous exposure to cigarette smoke resulted in an increased incidence of mutations in CYP2A6 gene which encoded cytochrome P450. In individuals with the low level of P450, the lifetime of nicotine elevated and could be fatal for body. Conversely, the situation did not provide a better benefit. High level of P450 in the body caused an increase of nicotine metabolism and had an adverse effect for the body [4].

Cytochrome P450 is an important enzyme in synthesis, metabolism, and elimination of cholesterol has an impact to the progression of atherosclerosis in many ways. Increased cholesterol stimulates P450 to removed excess cholesterol to conserve cholesterol homeostasis and atheroprotection. Several compounds induce P450 and other genes regulate cholesterol stability and intercept or degenerate atherosclerosis, whereas obstruction of P450 suppresses oxidative reactions and elevates atherogenesis [6].

This study aimed to determine the activity of cytochrome P450 to cigarette smoke exposure and to cholesterol level.

\section{Materials and Methods}

This research was an experimental study with a posttest-only control group design. This study was conducted in Animal House of Medical Faculty, Andalas University, from October 2019 to May 2020. The population of the study was male rat which originated from the maintenance unit of experimental animal. A total of 32 white male rats (Rattus norvegicus) Wistar albino strain aged 8-10 weeks were randomly selected and divided into four groups. Each group consisted of eight rats with two dropouts in every group.

Control group $(\mathrm{K})$ was a group with only given food and drink without any treatment. Treatment groups (P1, P2, and P3) were the experimental group with treatment. P1 group was a group which exposed to 2 cigarettes/day, P2 with 3 cigarettes/day, and P3 was exposed to 4 cigarettes/day. The content of nicotine per cigarette was $1 \mathrm{mg}$ nicotine. The treatment followed the reproductive cycle of male rats for 57 days. The rat blood was collected on the $58^{\text {th }}$ day through retroorbital; rats previously were given anesthetic ketamine. The blood then was transferred into a vacutainer and centrifuged at $3000 \mathrm{rpm}$ for $15 \mathrm{~min}$ to obtain serum.

Activity of cytochrome P450 was analyzed by enzyme-linked immunosorbent assay method. The data which resulted in from histopathological observations were analyzed using SPSS version 20.0. Normality test by Shapiro-Wilk test was done to determine normal distribution ( $\mathrm{n} \leq 50$ ). Normally distributed data were continued to one way ANOVA parametric test method. Conversely, Kruskal-Wallis nonparametric test was used if data were not normally distributed. Hypothesis was considered as significant if $p<0.05$ and then followed by a post-hoc least significant difference (LSD) analysis to determine the differences between treatment groups.

This study has been approved by Ethics Committee of Medical Faculty, Andalas University number: 490/KEP/FK/2019.

\section{Results}

\section{Assumption test}

The results of the normality test for P450 activity and cholesterol levels variable showed that the data were normally distributed ( $p>0.05 ; 0.067$ for cholesterol levels and 0.173 for P450 activity).

\section{Hypothesis test}

The result of the one-way ANOVA test was presented in Table 1.

Table 1: Result of one way ANOVA test for cholesterol and P450 activity

\begin{tabular}{llll}
\hline & $\mathrm{n}$ & $\mathrm{F}$ & $\mathrm{Sig}$ \\
\hline Cholesterol & 32 & 359.232 & $0.000^{*}$ \\
$\mathrm{p} 450$ activity & 32 & 3.148 & $0.044^{*}$ \\
\hline${ }^{*} \mathrm{p}>0.05$ & & &
\end{tabular}

Both cholesterol level and P450 activity have significant results $(p>0.05 ; p=0.000$ and $p=0.044$, respectively). Data were then analyzed using the posthoc LSD test to discover the different effects which received by each group.

The result in Tables 2 and 3 showed that the more number of cigarettes given, the more severe impact to the body. The activity of P450 showed that there was a significant difference between control and treatment groups, while in cholesterol variable, a significant difference was showed only in the control group toward treatment 2 and 3 .

Table 2: Post-hoc LSD test of cholesterol level inter groups

\begin{tabular}{|c|c|c|c|c|c|}
\hline \multirow[t]{2}{*}{ Dependent variable } & \multirow[t]{2}{*}{ (I) group } & \multirow[t]{2}{*}{ (J) group } & \multirow[t]{2}{*}{ Sig. } & \multicolumn{2}{|c|}{$95 \%$ confidence interval } \\
\hline & & & & Lower bound & Upper bound \\
\hline \multirow[t]{12}{*}{ Cholesterol } & $\mathrm{K}$ & $\mathrm{P} 1$ & 0.000 & -16.1083 & -11.5888 \\
\hline & & P2 & 0.000 & -26.1112 & -21.5917 \\
\hline & & P3 & 0.000 & -36.7069 & -32.1874 \\
\hline & P1 & $\mathrm{K}$ & 0.000 & 11.5888 & 16.1083 \\
\hline & & P2 & 0.000 & -12.2626 & -7.7431 \\
\hline & & P3 & 0.000 & -22.8583 & -18.3388 \\
\hline & P2 & $\mathrm{K}$ & 0.000 & 21.5917 & 26.1112 \\
\hline & & P1 & 0.000 & 7.7431 & 12.2626 \\
\hline & & P3 & 0.000 & -12.8555 & -8.3359 \\
\hline & P3 & $\mathrm{K}$ & & 32.1874 & 36.7069 \\
\hline & & P1 & & 18.3388 & 22.8583 \\
\hline & & P2 & & 8.3359 & 12.8555 \\
\hline
\end{tabular}


Table 3: Post-hoc LSD test of P450 inter groups

\begin{tabular}{llllll}
\hline Dependent variable & (I) group & (J) group & Sig. & \multicolumn{2}{c}{ 95\% confidence interval } \\
\cline { 5 - 6 } & & & & Lower bound & Upper bound \\
\hline P450 cytochrome & K & P1 & 0.112 & -0.3484 & 3.1344 \\
& & P2 & 0.010 & 0.6273 & 4.1101 \\
& & P3 & 0.021 & 0.3512 & 3.8340 \\
& P1 & K & 0.112 & -3.1344 & 0.3484 \\
& & P2 & 0.259 & -0.7657 & 2.7171 \\
& P2 & P & 0.415 & -1.0418 & 2.4410 \\
& & P1 & 0.010 & -4.1101 & -0.6273 \\
& & P3 & 0.259 & -2.7171 & 0.7657 \\
& P3 & K & 0.746 & -2.0175 & 1.4652 \\
& & P1 & 0.415 & -2.8340 & -0.3512 \\
& & P2 & 0.74 & -1.4652 & 1.0418 \\
\hline
\end{tabular}

\section{Discussion}

\section{levels}

\section{Cigarette smoke exposure and cholesterol}

Cigarette smoke exposure in humans had a fairly strong correlation, especially with the increase of lipid and homocysteine profiles, which were the main triggers for atherosclerosis [7]. In line with these findings, there was a significant effect of cigarette smoke exposure to the increasing of cholesterol levels in rats. It could be due to high lipolysis activity by nicotine metabolic activity in body. Haragopal and Aruna [8] found that nicotine in cigarette tobacco-induced the adrenal medulla to release catecholamine. High levels of catecholamine in blood directly influenced the increase of lipolysis of triglycerides stored in adipose and trigger an elevation of free fat acid secretion into blood.

There was still a debate about the components of lipid profile as a marker of the presence of nicotine response in body. Alharbi [9] found that there was an increase in the average of cholesterol level in smokers and non-smokers. Another study conducted by Hassan et al. [10] revealed that an increase in the period of exposure (years) increased the incidence of dyslipidemia and cholesterol levels and could be a determinant of various pathological incidence such as atherosclerosis which causes coronary heart disease.

The increase of pathological incidence such as atherosclerosis, increased cholesterol levels, and coronary heart disease experienced by individuals exposed to cigarette smoke was closely related to the length of exposure time and intensity of smoking cigarettes. This study was also found that the more number of cigarettes given to rats, the higher cholesterol levels. Similar finding published Digiacomo et al. [11] who found that the more intensity and duration of smoking, the heavier impact on the body. Negative effects on multiple tissues and increased the risk of various pathological occurrence and inflammatory symptoms were found. The pathogenesis findings occurrence reflected a series of lipolysis and the induction of free radical enzymes such as Nitrogen Oxides (NOX) and oxide of carbon (COX) which increased free radical levels (reactive oxygen species) [12]

\section{Cigarette smoke exposure and P450} activity

The lowering of various metabolic enzyme levels included P450, was evidence of the effect of nicotine regulation in body. A decrease level of an enzyme indicated an imbalance work of system, and it found in this study. There was a different activity found in the decrease of P450 enzyme in the treatment group.

P450 enzyme has an important role in the metabolism of nicotine. Bao et al. [3] found that P450 played a role in the metabolic pathway of nicotine and changed it into a low toxic substance. Aromatase P450 acted on the catalytic pathway to convert nicotine into intermediate nicotine- $\Delta-1$ ' (5') - iminium ion. The increase of nicotine in the body induced various free radical pathways as a negative onset of liver function which resulted in a decrease in P450. Another study conducted by Hukanen et al. [13] reported that brief exposure to nicotine had no significant effect on P450 activity, but this probably due to the differences in body's ability to accommodate toxic types entered a body system. A different finding was reported by Kwiecień et al. [5] found that P450 played a role in regulating nicotine into a material that was easy to eliminate from the body.

In another study, Li et al. [14] reported that from various enzyme groups, P450 group had an important role in metabolizing nicotine products, especially those found in cigarettes. P450 was also active as a catalyst in the steroidogenesis pathway or steroid hormone metabolism and drug metabolism.

The higher the nicotine level, the lower the P450 level, as a result of decreased liver function due to the accumulation of various free radical enzymes such as NOX and COX. In regulating cigarette smoke exposure to both individual smokers and non-smokers, various imbalances occurred in the body system. As a form of real physiological manifestation, namely an increase in various free radicals in the body, resulted in a state of oxidative stress in cells [6].

The decrease of P450 function directly caused an increase of lipolysis as a result of a decrease in various hormone functions, especially steroid hormones and an increase in lipid secretion in blood. In this is, of course, the function of various organs will be hampered, the formation of embolism and atherosclerosis which leads to impaired heart function. Furthermore, the incidence of hypogonadism and infertility can be clinical manifestations as a result of the decline in function of p450 [15]. 


\section{Conclusion}

This study concluded that cigarette smoke exposure significantly has an impact on increasing serum cholesterol levels and decreasing P450 enzyme activity in rats. Increasing the number of cigarettes affected significantly both smoker and non-smoker groups.

\section{Acknowledgments}

The authors would like to thank Dean of Faculty of Medicine, Andalas University of Padang. All staffs in Biomedical Laboratory, Medical Faculty of Andalas University, Padang.

\section{References}

1. Drajem M, Woellert L. Southeast Asia tobacco control alliance. In: Clove Cigarettes May Prompt U.S., Indonesia Dispute; 2019. Available from: https://www.seatca.org/clove-cigarettesmay-prompt-u-s-indonesia-dispute. [Last accessed on 2020 Dec 08].

2. National Institute of Health Research and Development (NIHRD). National Report on Basic Health Research (RISKESDAS) 2018; 2018. Available from: http://www.depkes.go.id/ resources/download/info-terkini/materi_rakorpop_2018/hasil \%20riskesdas\%202018.pdf. [Last accessed on 2019 Feb 19].

3. Bao Z, He XY, Ding X, Prabhu S, Hong JY. Metabolism of nicotine and cotinine by human cytochrome P450 2A13. Drug Metab Dispos. 2005;33(2):258-61. https://doi.org/10.1124/ dmd.104.002105

PMid:15528319

4. Papathanasiou G, Mamali A, Papafloratos S, Zerva E. Effects of smoking on cardiovascular function: The role of nicotine and carbon monoxide. Health Sci J. 2014;8(2):272-88.

5. Kwiecień RA, Le Questel JY, Lebreton J, Delaforge M, André F,
Pihan E, et al. Cytochrome P450-catalyzed degradation of nicotine: Fundamental parameters determining hydroxylation by cytochrome P450 2A6 at the 5'-carbon or the N-methyl carbon. J Phys Chem B. 2012;116(27):7827-40. https://doi.org/10.1021/ jp304276v

\section{PMid:22676413}

6. Luoma PV. Elimination of endoplasmic reticulum stress and cardiovascular, type 2 diabetic, and other metabolic diseases. Ann Med. 2013;45(2):194-202. https://doi.org/10.3109/0785389 0.2012 .700116

PMid:22928964

7. Singh D. Effect of cigarette smoking on serum lipid profile in male population of Udaipur. Biochem Anal Biochem. 2016;5(3):1-3. https://doi.org/10.4172/2161-1009.1000283

8. Haragopal R, Aruna BM. Effects of tobacco chewing on serum lipid profile in South Indian population. Int J Sci Study. 2016;4(4):9-14

9. Alharbi WD. Influence of cigarette smoking on lipid profile. Pak J Pharmacol. 2011;28(2):45-9.

10. Hassan EE, Gabra HM, Abdalla ZA, Ali AE. Effect of cigarette smoking on lipid profile in male at collage of police and Low Khartoum, Sudan. Asian J Biomed Pharm Sci. 2013;26:28-31.

11. DiGiacomo SI, Jazayeri MA, Barua RS, Ambrose JA. Environmental tobacco smoke and cardiovascular disease. Int J Environ Res Public Health. 2018;16(1):96. https://doi. org/10.3390/ijerph16010096 PMid:30602668

12. Phaniendra A, Jestadi DB, Periyasamy L. Free radicals: Properties, Sources, targets, and their implication in various diseases. Indian J Clin Biochem. 2015;30(1):11-26. https://doi. org/10.1007/s12291-014-0446-0 PMid:25646037

13. Hukkanen $J$, Jacob $P \quad 3^{\text {rd }}$, Peng $M$, Dempsey $D$ Benowitz NL. Effect of nicotine on cytochrome P450 1A2 activity. Br J Clin Pharmacol. 2011;72(5):836-8. https://doi. org/10.1111/j.1365-2125.2011.04023.x

PMid:21599724

14. Li Z, Jiang Y, Guengerich FP, Ma L, Li S, Zhang W. Engineering cytochrome P450 enzyme systems for biomedical and biotechnological applications. J Biol Chem. 2020;295(3):83349. https://doi.org/10.1074/jbc.rev119.008758 PMid:31811088

15. Sagar R, Kumar A, Misra S, Kumar P, Raj R, Gulati A, et al. Relationship between cytochrome P450 G1347A gene polymorphism and risk of ischemic stroke in North Indian population: A case-control study. J Neurol Neurosci. 2019;10(2):297. https://doi.org/10.36648/2171-6625.10.2.297 